\title{
Fixation of Penicilloyl Groups to Albumin and Appearance of Anti-Penicilloyl Antibodies in Penicillin-treated Patients
}

\author{
Pierre Lafaye and Claude Lapresle \\ Service d'Immunochimie des Protéines, Institut Pasteur, Paris Cédex 15, France
}

\begin{abstract}
Penicilloyl groups, which have been connected to penicillin allergy, are derived from penicillin by cleavage of the $\beta$ lactam ring and bind covalently to proteins. Fixation of penicilloyl groups was studied in seven patients given large amounts of penicillin. Penicilloyl groups were found essentially on the albumin molecule at sites not accessible to anti-penicilloyl antibodies, except after pronase digestion. The amount of penicilloyl groups was proportional to the cumulated doses of penicillin. The decline of penicilloyl groups with time after treatment interruption was exponential. The half-life of penicilloylated albumin was lower than or equal to that of normal albumin. The presence of anti-penicilloyl antibodies was demonstrated in 19 out of 34 penicillin-treated patients (including the seven mentioned above). The relative scarcity of penicillin allergy as compared with the frequent occurrence of anti-penicilloyl antibodies may be partly related to unavailable sites of penicilloyl groups within the albumin molecule.
\end{abstract}

\section{Introduction}

Transient bisalbuminemia due to the presence of a fast albumin component in the serum of patients receiving large amounts of penicillin was first described by Arvan et al. (1). Normal and fast albumin were subsequently separated by ionic exchange chromatography and the presence of penicilloyl groups (BPO ${ }^{1}$ groups) was ascertained on fast albumin using RIA $(2,3)$ and ELISA (4).

BPO groups derived from penicillin by cleavage of the $\beta$ lactam ring bind covalently to proteins, giving rise to compounds devoid of antibacterial activity. Two fixation sites for BPO groups have been demonstrated on the albumin molecule and their location has been partly specified (5).

This phenomenon is of particular interest because it is an example of a drug-induced modification of human albumin. Furthermore, many authors have long suspected BPO groups to be involved in the pathogenesis of penicillin allergy (6-8).

In the present study, we investigated fixation of BPO

Address reprint requests to Dr. Claude Lapresle, Service d'Immunochimie des Protéines, Institut Pasteur, 28 rue du Dr. Roux, Paris, Cédex 15, France.

Received for publication 26 October 1987 and in revised form 13 January 1988.

1. Abbreviations used in this paper: BPO, penicilloyl; BPO Tr, penicilloylated transferrin; NHS, normal human serum; PAP, penicilloylated alkaline phosphatase; $P \in A C$, penicilloyl $\epsilon$-aminocaproate.

J. Clin. Invest.

(c) The American Society for Clinical Investigation, Inc.

0021-9738/88/07/0007/06 \$2.00

Volume 82, July $1988,7-12$ groups to serum proteins in the sera of seven patients receiving large amounts of penicillin. Moreover, we looked for formation of anti-penicilloyl antibodies in the sera of 34 patients (including the seven noted above) treated with penicillin.

\section{Methods}

Sera were collected from patients receiving penicillin $G$ (benzyl penicillin sodium; Specia, Paris, France) at the hospital of the Institut Pasteur. Normal human serum (NHS) was collected from a subject who had never received penicillin.

Electrophoresis in polyacrylamide-agarose composite gels was carried out in Tris-glycine buffer ( $\mathrm{pH}$ 8.7) with plates (Indubiose; Industrie Biologique Française, Paris, France) as described by Uriel (9).

Nonalbumin and albumin fractions of the sera were separated according to Travis et al. (10) by affinity chromatography on Cibacron Blue using the procedures recommended by the manufacturer (Pharmacia Fine Chemicals, Uppsala, Sweden). Sera were dialyzed against $0.05 \mathrm{M}$ Tris- $\mathrm{HCl}$ buffer at $\mathrm{pH} 7.0$ containing $0.1 \mathrm{M} \mathrm{KCl}$ and applied to a column of Cibacron Blue Sepharose Cl-6B equilibrated with the same buffer. A first fraction, eluted with the starting buffer, contained the nonalbumin fractions of serum and traces of albumin; a second fraction, eluted with $0.05 \mathrm{M}$ Tris- $\mathrm{HCl}$ buffer at $\mathrm{pH} 7.0$ containing 1.5 $\mathrm{M} \mathrm{KCl}$, contained practically all the albumin. The amount of protein was measured using the biuret reagent of Weichselbaum (11), taking as a reference the standard curve established with HSA.

The two fractions of the sera were digested by pronase (Calbiochem-Behring Corp., La Jolla, CA) as described by Lapresle and Wal (3). Digestion of the sera by pronase was carried out using similar conditions $(0.1 \mathrm{ml}$ serum and $10 \mathrm{U}$ pronase).

BPO groups were measured using the ELISA described by Lapresle and Lafaye (4). Briefly, this ELISA consisted of allowing penicilloylated alkaline phosphatase (PAP) to react with immobilized anti-penicilloyl antibodies. Rabbit anti-penicilloyl antibodies were isolated as described by Lafaye and Lapresle (5). Inhibition reference curves were established with two samples of penicilloylated HSA containing known amounts of BPO groups, penicilloyl polylysin (Cilligen), and penicilloyl $\epsilon$-aminocaproate $(\mathrm{P} \in \mathrm{AC}$ ) (Sigma Chemical Co., St. Louis, MO) (Fig. 1). The amount of penicillin was measured as the amount of penicilloylated protein giving $50 \%$ inhibition with reference to the amount of $P \epsilon A C$ giving $50 \%$ inhibition.

Detection of the IgM, IgG, and IgE anti-penicilloyl antibodies was performed using an ELISA technique as modified from Engvall and Perlman (12). The following buffers were used: buffer A, $0.01 \mathrm{M}$ potassium phosphate (pH 7.4), $0.15 \mathrm{M} \mathrm{NaCl}$, and $0.1 \%$ (vol/vol) Tween 20; buffers $B$ and $C$, which in addition to the components of buffer $A$, contained, respectively, $2 \%(\mathrm{wt} / \mathrm{vol})$ and $0.5 \%(\mathrm{wt} / \mathrm{vol})$ gelatin. All dilutions were made in buffer $\mathrm{C}$. Titration plates possessing 96 flatbottomed wells $(1.0 \times 0.6 \mathrm{~cm})$ were purchased from Nunc (Roskilde, Denmark). In each well of a microtitration plate, $0.1-\mathrm{ml}$ quantities of penicilloylated transferrin (BPO $\mathrm{Tr})(5 \mu \mathrm{g} / \mathrm{ml})$ were incubated at $37^{\circ} \mathrm{C}$ for $1 \mathrm{~h}$ and then overnight at $4^{\circ} \mathrm{C}$. BPO $\operatorname{Tr}$ was prepared with human transferrin (98\% pure) (Sigma Chemical Co.) by the same procedure as used by Wal et al. (2) for preparing penicilloylated bovine $\gamma$ globulin. The coated plates were thoroughly washed with buffer A. Saturation of each well was carried out with $0.1 \mathrm{ml}$ of buffer $B$ for $1 \mathrm{~h}$ at $37^{\circ} \mathrm{C}$. Plates were washed six times with buffer $A$. Then, $0.1 \mathrm{ml}$ of the sera diluted 


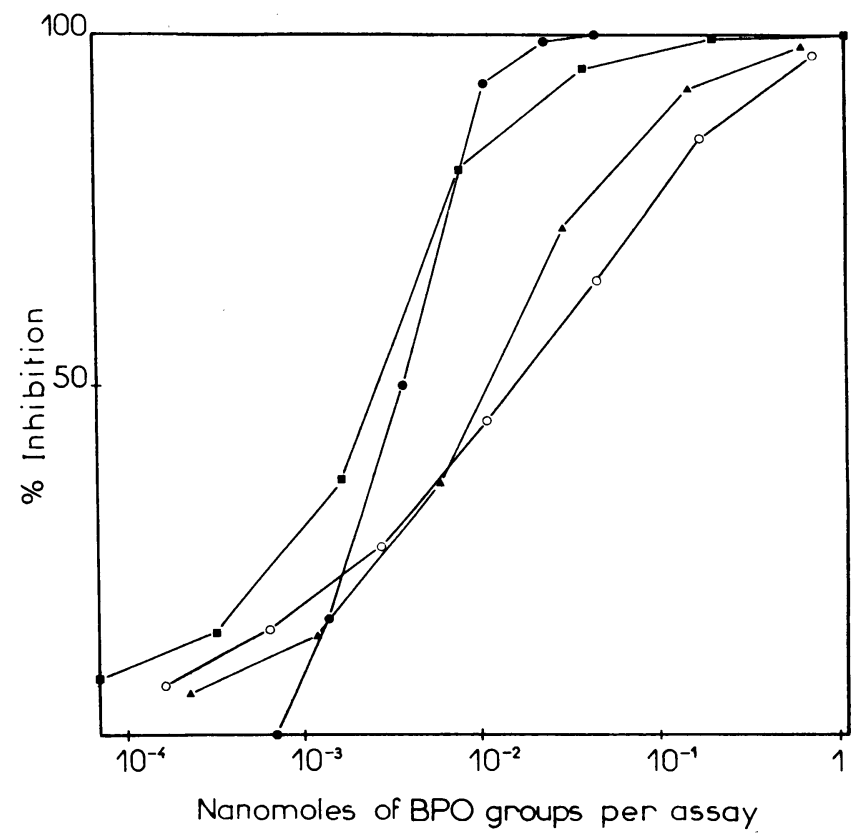

Figure 1. Inhibition of the reaction of PAP with coated anti-penicilloyl antibodies. Inhibitors: HSA containing one BPO group per molecule ( $\triangle$ ), HSA containing 2.53 BPO groups per molecule ( $\square$ ), penicilloylated polylysin containing $0.12 \mathrm{mmol} /$ liter $(\bullet)$, and penicilloyl $\epsilon$ aminocaproate containing $7 \mathrm{mmol} / \mathrm{liter}(\mathrm{O})$.

1:50 was pipetted into wells and incubated for $2 \mathrm{~h}$ at $37^{\circ} \mathrm{C}$. The plates were washed six times with buffer A. $0.1 \mathrm{ml}$ of sheep anti-human IgM or IgG coupled to alkaline phosphatase (Biosys, Compiègne, France) or goat anti-human IgE coupled to horseradish peroxydase (Nordic Immunology, Tilburg, The Netherlands) was then added to the wells. To remove any possible traces of antibodies reacting with BPO $\mathrm{Tr}$, antibodies were filtered through an immunoaffinity column. The dilutions at which these antibodies were used were established in previous experiments as the amount of antibodies giving the higher ratio between the tested serum and NHS. Sheep anti-human IgG and IgM were diluted to 1:500 and 1:400, respectively, and goat anti-human IgE was diluted to 1:200. Phosphatase alkaline activity was measured by adding $0.1 \mathrm{ml}$ of $10^{-3} \mathrm{M} p$-nitrophenyl phosphate in $0.1 \mathrm{M}$ Tris- $\mathrm{HCl}$ buffer ( $\mathrm{pH} \mathrm{8.0)}$ containing $1.5 \mathrm{M} \mathrm{NaCl}$. The color was read at $405 \mathrm{~nm}$ (13). Peroxydase activity was measured by adding $0.1 \mathrm{ml}$ of a solution $\left(0.4 \mathrm{mg} / \mathrm{ml}\right.$ in $25 \mathrm{mM}$ citrate buffer, $\mathrm{pH} 5.0$, containing $0.2 \mu \mathrm{l} / \mathrm{ml} \mathrm{H}_{2} \mathrm{O}_{2}$ $30 \%$ ) containing 0 -phenylenediamine (Sigma Chemical Co.). The reaction was stopped after $15 \mathrm{~min}$ by the addition of $50 \mu \mathrm{l}$ of $2 \mathrm{~N} \mathrm{H}_{2} \mathrm{SO}_{4}$ and the color developed was read at $492 \mathrm{~nm}$. Sera were considered to be positive when the color intensity was at least twice the color intensity yielded by the serum of the same patient before penicillin injection. All sera collected before penicillin therapy gave a color intensity ranging from 0.040 to 0.090 .

In vitro experiments. Aliquots of NHS were mixed with a constant amount of penicillin $\mathrm{G}\left(10^{4} \mathrm{IU}\right.$ penicillin $\mathrm{G} / \mathrm{ml}$ serum $)$ and allowed to remain at $37^{\circ} \mathrm{C}$ for increasing periods of time. The various aliquots were dialyzed against ice-cold $0.15 \mathrm{M} \mathrm{NaCl}$ for $24 \mathrm{~h}$ and kept frozen. The amount of BPO groups was determined on the whole sera and on the albumin and nonalbumin fractions of the sera separated as described above by affinity chromatography on Cibacron Blue.

\section{Results}

Subjects were distributed as follows: $(a)$ seven patients treated with large amounts of penicillin, in whom the fixation of BPO groups and production of anti-penicilloyl antibodies were systematically investigated in the course of and after penicillin therapy; (b) 27 patients who received varying amounts of penicillin, in whom anti-penicilloyl antibodies were looked for after the treatment; and $(c)$ one subject who had never received penicillin, whose serum was used for in vitro experiments.

\section{In vivo studies}

Table I gives the clinical data of the seven patients treated by large amounts of penicillin $\mathrm{G}$.

Measurement of penicilloyl groups in the serum before and after enzymatic degradation. Fig. 2 gives as an example the amount of BPO groups in the serum of patient LOT in the course of and after penicillin therapy. Before digestion with pronase, the number of detectable BPO groups was low. As a result of pronase digestion, the amount of BPO groups increased dramatically. It increased regularly as penicillin therapy was pursued and decreased exponentially as a function of time when penicillin administration was interrupted. The six other sera gave similar curves. Taking into account the effect of enzymatic digestion, the successive experiments were all carried out on sera and fractions thereof subjected to pronase digestion.

Amount of BPO groups fixed to the fractions of the sera. Nonalbumin and albumin fractions of the seven sera were separated by chromatography on a Cibacron Blue Sepharose. Fig. 3 shows the amount of BPO groups bound to these two fractions as a function of the cumulated doses of penicillin. It can be seen that $\sim 90 \%$ of BPO groups were fixed to albumin. The amount of BPO groups increased linearly and similarly from one serum to the other with the cumulated amount of

Table I. Clinical Data about the Seven Patients Receiving Large Doses of Penicillin G

\begin{tabular}{llccc}
\hline Name & \multicolumn{1}{c}{ Diseases } & $\begin{array}{c}\text { Amount of penicillin G } \\
\text { per day } \times 10^{6} \mathrm{IU}\end{array}$ & $\begin{array}{c}\text { Total amount of penicillin } \\
\mathbf{G} \times 10^{6} \mathrm{IU}\end{array}$ & \multicolumn{1}{c}{ Remarks } \\
\hline FAU & Bacterial endocarditis (causal agent not isolated) & 50 & 600 \\
GER & Meningitis (Listeria monocytogenes) & 40 & 1,000 \\
LEV & Bacterial endocarditis (Streptococcus faecalis) & 50 & 1,900 & Glomerular nephropathy \\
LOI & Bacterial endocarditis (Streptococcus faecalis) & 45 & 1,215 & \\
LOT & Bacterial endocarditis (Actinobacillus & 50 & 850 & Allergic rash to penicillin \\
& actinomycetemcomitans) & 50 & 350 & 200 \\
PIE & Fever of unknown etiology & 40 & &
\end{tabular}




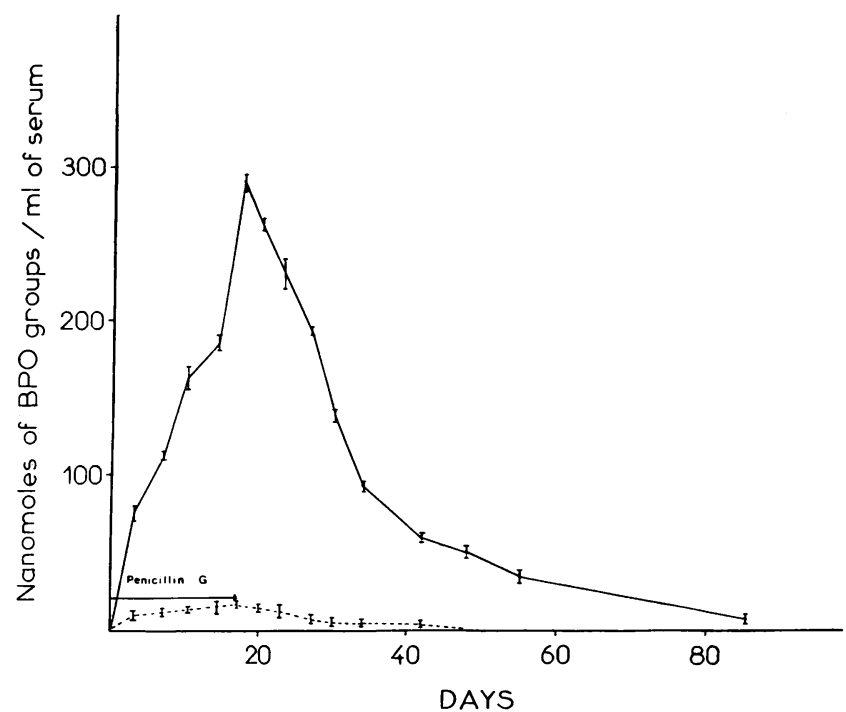

Figure 2. Typical curve of the amount of BPO groups in the serum of a penicillin-treated patient (LOT) before (-- ) and after (-) pronase digestion.

penicillin. In the conditions of the regimen used, BPO groups failed to saturate all fixation sites on albumin.

Decrease of penicilloylated albumin after penicillin therapy. Fig. 4 shows the decrease of penicilloylated albumin as a function of time after interruption of penicillin administration. On a semilogarithmic scale, the seven curves are linear, with slopes varying from one subject to the other. The half-life of penicilloylated albumin was calculated from these curves (Table II) as equal to or lower than the half-life of albumin (20 d) (14).

BPO groups could be detected for a very long time; in one case (VIC), traces of BPO groups were still present $330 \mathrm{~d}$ after initiation of the treatment.

Measurement of anti-penicilloyl antibodies. Antibodies of the three classes, IgM-, IgG-, and IgE-specific for BPO groups, were searched for in the sera of the seven patients. Results are summarized in Table II. In three patients (GER, LEV, and LOT), no anti-penicilloyl antibodies were detected. In three others (FAU, LOT, and PIE) the presence of anti-penicilloyl antibodies of the IgG class could be demonstrated. In only one of these (VIC) antibodies belonging to the three classes were present. It should be remembered that this was the serum of a patient whose treatment was interrupted because of the occurrence of penicillin allergy.

Note that in the five patients whose penicilloylated albumin exhibited a shorter half-life than that of albumin, four (FAU, LOI, PIE, and VIC) gave an antibody response and only one (LOT) had no detectable anti-penicilloyl antibodies. The two patients (GER and LEV) whose penicilloylated albumin showed a half-life close to that of albumin, did not have antipenicilloyl antibodies.

In addition, detection of anti-penicilloyl antibodies was performed in sera from 27 other patients who received, for various reasons, amounts of penicillin ranging from $4 \times 10^{6}$ to $1,824 \times 10^{6} \mathrm{IU}$. Among them, 15 were found positive. Table III gives the distribution of the anti-penicilloyl antibodies among the different classes.

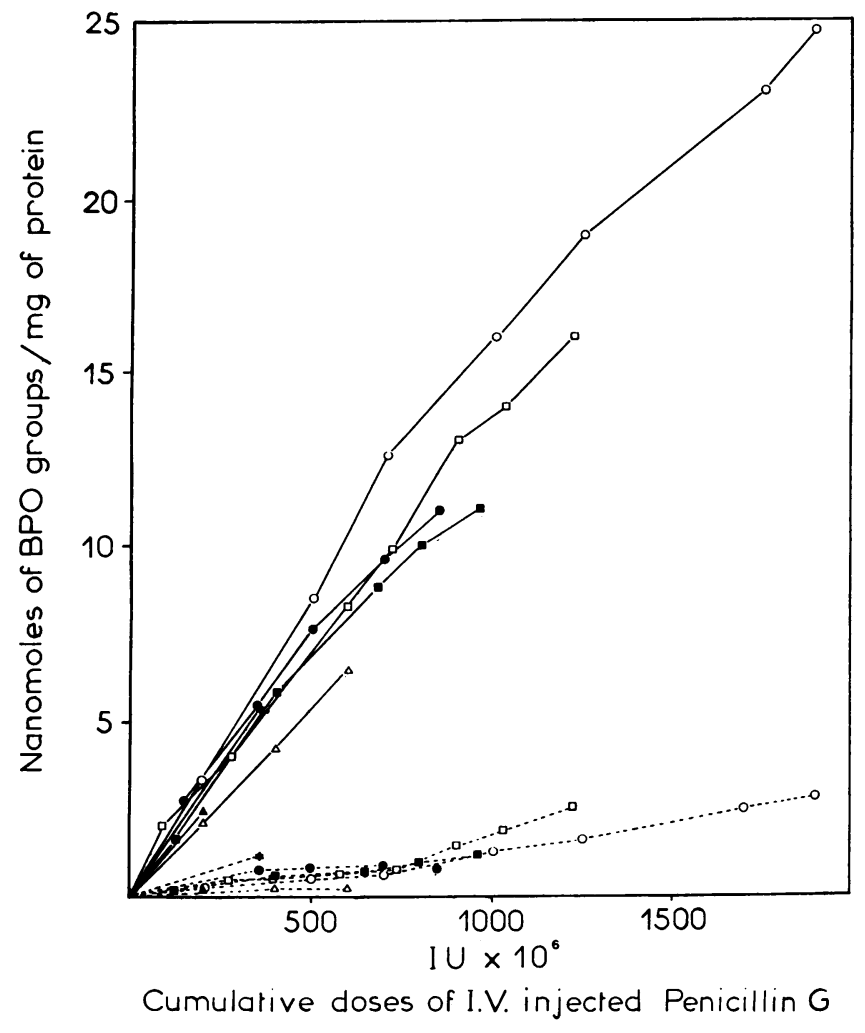

Figure 3. Amount of BPO groups in albumin ( - and nonalbu$\min (---)$ fractions from seven penicillin-treated patients. $\triangle$, FAU;

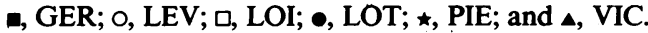

\section{In vitro studies}

Aliquots of NHS were mixed with a constant amount of penicillin $\left(10^{4} \mathrm{IU}\right.$ penicillin/ml $)$ during various periods of time. As Fig. 5 shows, bisalbuminemia was evident at the sixth hour, and at $24 \mathrm{~h}$ all the albumin consisted of only the fast component. The electrophoretic pattern of the serum of patient LEV, who received the largest amount of penicillin, is given for com-

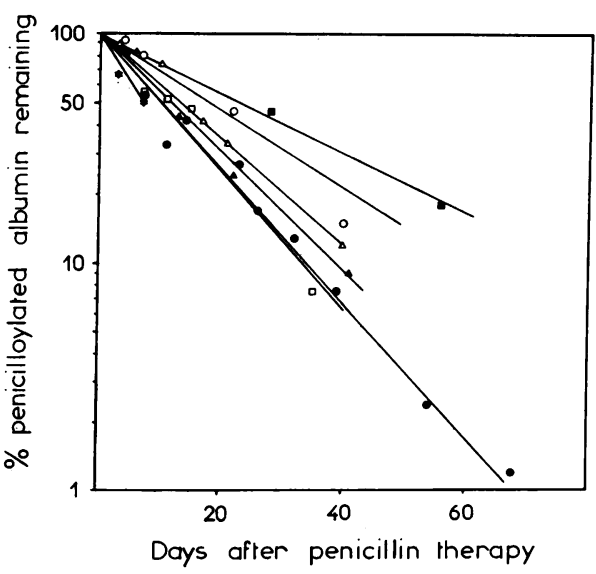

Figure 4. Decline of penicilloylated albumin in the sera of seven patients after interruption of penicillin therapy. $\triangle$, FAU; $\approx$, GER; $O$,

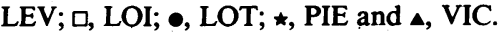


Table II. Anti-Penicilloyl Antibody Production and Half-life of Penicilloylated Albumin in Sera of the

Seven Patients Receiving Large Amounts of Penicillin G

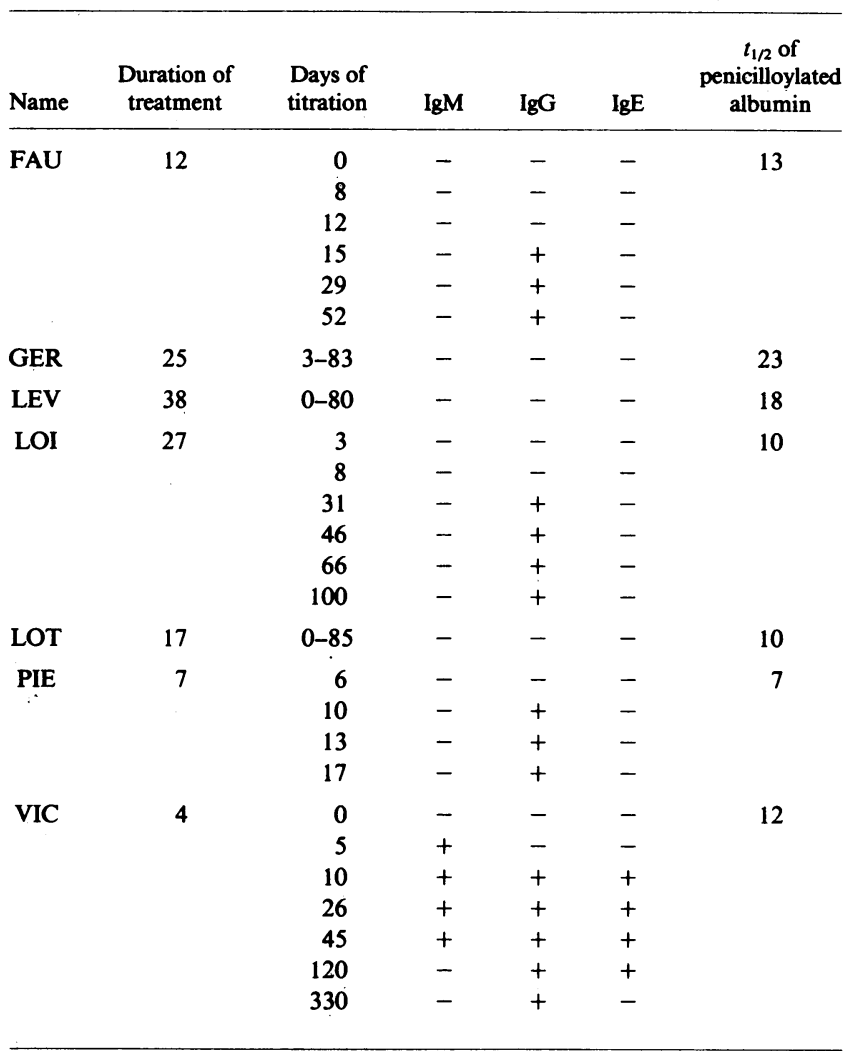

parison. His serum was obtained at the end of treatment and contained both normal and fast albumins.

After addition of penicillin to the sample of NHS, it was found that BPO groups increased regularly with time (Table IV). They were essentially fixed to the albumin fraction, and their number was much increased by pronase digestion. On the contrary, pronase digestion increased only slightly the number of BPO groups of the nonalbumin fraction.

\section{Discussion}

The amount of BPO groups was measured using an immunoassay based upon the inhibition of the reaction between coated anti-penicilloyl antibodies and PAP. Inhibition by the different sera or fractions thereof was estimated with respect to a reference curve (Fig. 1). Reference curves were previously established with two albumin derivatives containing different numbers of BPO groups (4). In fact, inhibition varied slightly depending on the number of BPO groups present on HSA, which is in agreement with the observations of Lee et al. (15). Consequently, two other penicilloyl derivatives containing a

Table III. Class of the Antibodies in the Sera of the 15 Penicillin-treated Patients Containing Anti-Penicilloyl Antibodies

\begin{tabular}{ccccc}
\hline $\operatorname{IgM}$ & $\operatorname{IgG}$ & $\operatorname{IgM}+\operatorname{IgG}$ & $\operatorname{IgG}+\operatorname{IgE}$ & $\operatorname{IgM}+\operatorname{IgG}+\operatorname{IgE}$ \\
\hline 2 & 5 & 6 & 1 & 1
\end{tabular}

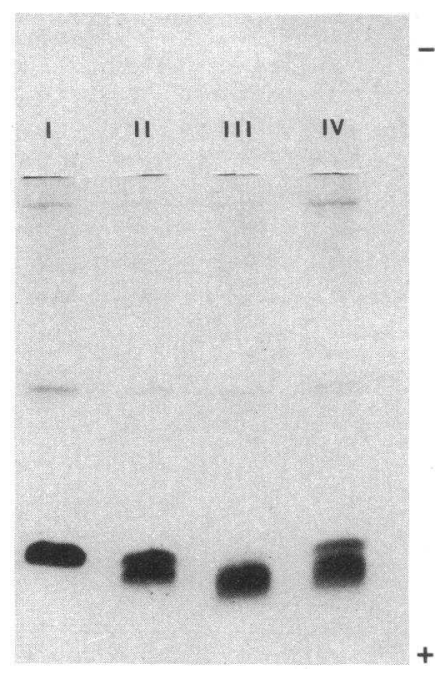

Figure 5. Electrophoresis in polyacrylamide-agarose composite gels of normal human serum mixed with penicillin $G$ at $\mathrm{O}$ (I), 6 (II), and $24 \mathrm{~h}$ (III) and of serum LEV after $38 \mathrm{~d}$ of treatment (IV). V/cm: 10 ; duration: $3 \mathrm{~h}$.

definite number of BPO groups, Cilligen and $\mathrm{P} \in \mathrm{AC}$, were tested. The latter was chosen since its curve ran parallel to the curves given by the penicilloylated albumins, which was not the case for Cilligen.

Several techniques were designed for detecting anti-penicilloyl antibodies: hemagglutination (16-18), viroimmunoassay (19), RIA (20), viroenzymo-immunoassay (21), and ELISA (22). In the present study, a modification of ELISA was worked out in plates. Attention focused on reduction of nonspecific reactions. Saturation of the wells was achieved with a high concentration of gelatin and all the tagged anti-antibodies were purified by immunoadsorption upon BPO Tr.

Administration of high doses of penicillin results in bisalbuminemia, which was related to the presence of penicilloylated albumin (3). This derivative exhibited greater mobility than normal albumin, most probably because the $\epsilon$-amino groups of albumin were blocked by negatively charged BPO groups. BPO groups were first determined using RIA (2) and ELISA (4) on fast albumin isolated from penicillin-treated patients. In the present study, although all the patients presented with bisalbuminemia (results not shown), no attempt was made to separate fast from regular albumin, since the main goal of our investigation was the study of the kinesis of BPO groups fixation on albumin at periods when the relative amount of fast albumin was still very low.

The main result, as previously reported, was that most BPO groups were located at sites on the albumin molecule that were not accessible to anti-penicilloyl antibodies unless the albumin molecule was degraded by enzymatic digestion (3). Here again, it was verified that enzymatic digestion of whole serum or fractions thereof was necessary to unmask all BPO groups present in the sera of penicillin-treated patients. If this procedure is not carried out, the number of BPO groups is likely to be largely underestimated.

Separation of albumin and nonalbumin proteins from the sera by affinity chromatography with Cibacron Blue showed that BPO groups were essentially present on albumin, which appears to play a prominent role in the fixation of these groups.

The number of BPO groups fixed per mole of albumin increased linearly as a function of the cumulated dose of penicillin; the fixation curve was not saturable. Saturation is likely 
Table IV. Amounts of BPO Groups Found in NHS and Fractions Thereof as a Function of Time after Addition of Penicillin

\begin{tabular}{|c|c|c|c|c|c|c|}
\hline \multirow[b]{2}{*}{ Hours } & \multicolumn{2}{|c|}{ Serum* } & \multicolumn{2}{|c|}{ Nonalbumin fraction ${ }^{\ddagger}$} & \multicolumn{2}{|c|}{ Albumin fraction ${ }^{\ddagger}$} \\
\hline & Not digested & Digested & Not digested & Digested & Not digested & Digested \\
\hline 0 & 0 & 0 & 0 & 0 & 0 & 0 \\
\hline 6 & 150 & 572 & 0.87 & 1.1 & 0.9 & 12 \\
\hline 24 & 660 & 1,568 & 5.3 & 6 & 4.8 & 30 \\
\hline
\end{tabular}

* Nanomoles of BPO groups/ml of serum. ${ }^{\ddagger}$ Nanomoles of BPO groups/mg of protein.

to require amounts of penicillin that are not acceptable in humans. The ratio of BPO groups per molecule of albumin did not differ significantly from one patient to the another, indicating that there is no individual difference in the capacity of albumin to react with BPO groups. The maximum ratio was observed in the patient LEV, who was treated for the longest period of time. This ratio (1.66) is slightly higher than that previously published in patients who received however smaller amounts of penicillin (3). It is consistent with the presence of at least two fixation sites for BPO groups in human albumin (5).

Estimation of the half-life of penicilloylated albumin yielded different results in the various patients. The half-life was shorter than that of albumin (20 d) in some patients. It is tempting to refer the accelerated catabolism of penicilloylated albumin to the presence of antibodies, as has previously been reported (23). In fact, anti-penicilloyl antibodies could not be detected in the two patients (GER and LEV) in whom the half-life of penicilloylated albumin was similar to that of albumin; whereas among the five patients in whom the half-life of penicilloylated albumin was shortened, anti-penicilloyl antibodies were found in four of them. The above hypothesis, however, provides no explanation for the absence of anti-penicilloyl antibodies in the patient (LOT) in whom the half-life of penicilloylated albumin was shortened. Moreover, this hypothesis is not easy to reconcile with the finding that most of penicilloyl groups in albumin are not readily accessible to antibodies. Therefore, further hypotheses deserve consideration, such as the one postulating the presence of antibodies directed against exposed minor components of penicillin different from penicilloyl groups. Such antibodies were described by Edwards et al. (24). Another hypothesis would assume a greater sensitivity to attack by proteolytic enzymes of penicillin-modified albumin with respect to that of native albumin.

The BPO groups fixed to albumin are derived from a very small proportion of penicillin, between 1 and $2 \%$ (3). That explains why this phenomenon does not appreciably affect the antibiotic activity of the drug. On the contrary, even at this low level, BPO groups coupled to albumin are antigenic in humans, because anti-penicilloyl antibodies were demonstrated in 19 out of the 34 penicillin-treated patients. This observation agrees with previous results $(25,26)$. A similar observation notes the derivatization of albumin by the $\beta$ propiolactone used in the rabies vaccine, resulting in a component that is seemingly antigenic in human (27). The high frequency of antibody response is probably related to protracted persistence of penicilloylated albumin. In addition, an undocumented history of penicillin treatment might play a role. In the case of VIC, in whom the penicillin treatment had to be inter- rupted after $4 \mathrm{~d}$ because of an allergic rash, the antibody response was anamnestic.

BPO groups and antipenicilloyl antibodies appear to coexist in the serum for several months. Yet allergic complications in the course of penicillin therapy are rare (26). In our series of seven patients, two (LOI and VIC), presented with complications having an immunological basis but these complications appear to be due to chance and are not as frequent, if one considers that out of 27 other patients, only two experienced an allergic rash. The scarcity of anti-penicilloyl IgE antibodies may, in part, account for the relative innocuousness of penicillin. More likely, this innocuousness results from the location of BPO groups on albumin at sites that are not readily available to antibodies.

Normal human serum was mixed in vitro with an amount of penicillin corresponding to $\sim 50 \times 10^{6}$ IU of penicillin $G$ diluted in 6 liters of circulating blood. Under these conditions, a bisalbuminemia similar to that observed in vivo was produced. After $24 \mathrm{~h}$, all the albumin consisted of the fast component. This situation was not observed in vivo, probably because there is a constant de novo synthesis of albumin molecules. The in vivo location of BPO groups within the albumin molecule could have been accounted for by assuming that BPO groups were fixed before completion of albumin synthesis. However, the finding that in vitro location is the same as that in vivo does not confirm this hypothesis and strongly suggests that fixation of BPO groups should be a post-translational event. The slow increase with time of BPO groups fixed on albumin is consistent with another example of post-translational modification of albumin, glucosylation, which is also a slow process (28). The number of BPO groups per molecule of albumin, 2 , is in the same range as that observed in vivo.

Results reported in this paper clearly show that fixation of BPO groups to albumin during penicillin therapy represents an attractive model for exploring the role of albumin and its possible involvement in protection toward drug allergy.

\section{Acknowledgments}

We appreciate the skillful technical assistance of Dominique Leduc and Josette Cavillon.

\section{References}

1. Arvan, D. A., B. S. Blumberg, and L. Melartin. 1968. Transient "bisalbumínemia" induced by drugs. Clin. Chim. Acta. 22:211-218.

2. Wal, J. M., G. Bories, S. Mamas, and F. Dray. 1975. Radioimmunoassay of penicilloyl groups in biological fluids. FEBS (Fed. Eur. Biochem. Soc.) Lett. 57:9-13. 
3. Lapresle, C., and J. M. Wal. 1979. The binding of penicillin to albumin molecules in bisalbuminemia induced by penicillin therapy. Biochim. Biophys. Acta. 586:106-111.

4. Lapresle, C., and P. Lafaye. 1985. Enzyme-linked immunosorbent assay for measurement of penicilloyl groups. Ann. Inst. Pasteur Immunol. 136C:375-382.

5. Lafaye, P., and C. Lapresle. 1987. Location of penicilloyl groups on $\mathrm{CNBr}$ fragments of the albumin from penicillin-treated patients. FEBS (Fed. Eur. Biochem. Soc.) Lett. 220:206-208.

6. Levine, B. B., and Z. Ovary. 1961. Studies on the mechanism of the formation of the penicillin antigen. III. The $N$-(D- $\alpha$-benzylpenicilloyl) group as an antigenic determinant responsible for hypersensitivity to penicillin G. J. Exp. Med. 114:875-904.

7. Parker, C. W., J. Shapiro, M. Kern, and H. N. Eisen. 1962. Hypersensitivity to penicillenic acid derivatives in human beings with penicillin allergy. J. Exp. Med. 115:821-838.

8. de Weck, A. L. 1963. Newer developments in penicillin immunochemistry. Int. Arch. Allergy Appl. Immunol. 22:245-252.

9. Uriel, J. 1966. Methode d'électrophorèse dans des gels d'acrylamide-agarose. Bull. Soc. Chim. Biol. 48:969-982.

10. Travis, J., J. Bowen, D. Tewksbury, D. Johnson, and R. Pannel. 1976. Isolation of albumin from whole human plasma and fractionation of albumin-depleted plasma. Biochem. J. 157:301-306.

11. Weichselbaum, T. E. 1946. An accurate and rapid method for the determination of proteins in small amounts of blood serum and plasma. Am. J. Clin. Pathol. 16(Tech. Sect. 10):40-49.

12. Engvall, E. and P. Perlmann. 1972. Enzyme-linked immunosorbent assay, ELISA. III. Quantification of specific antibodies by enzyme-labeled anti-immunoglobin in antigen-coated tubes. J. Immunol. 109:129-135.

13. Garen, A. and C. Levinthal. 1960. A fine-structure genetic and chemical study of the enzyme alkaline phosphatase of $E$. coli. I. Purification and characterisation of alkaline phosphatase. Biochim. Biophys. Acta. 38:470-483.

14. Peters, T. 1970. Serum albumin. Adv. Clin. Chem. 13:37-111.

15. Lee, D., J. M. Dewdney, and R. G. Edwards. 1985. The influence of hapten density on the assay of penicilloylated proteins in fluids. J. Immunol. Methods. 84:235-243.

16. de Weck, A. L. 1964. Penicillin allergy: its detection by an improved hemagglutination technique. Nature (Lond.). 202:975-977.
17. Thiel, J. A., S. Mitchell, and C. W. Parker. 1964. The specificity of hemagglutination reactions in human and experimental penicillin hypersensitivity. J. Allergy. 35:399-424.

18. Levine, B. B., M. J. Fellner, and V. Levytska. 1966. Benzylpenicilloyl specific serum antibodies to penicillin in man. I. Development of a sensitive hemagglutination assay method and haptenic specificities of antibodies. J. Immunol. 96:707-718.

19. Haimovich, J., M. Sela, J. M. Dewdney, and F. R. Batchelor. 1967. Anti-penicilloyl antibodies: detection with penicilloylated bacteriophage and isolation with a specific immunoadsorbent. Nature (Lond.). 214:1369-1370.

20. Wide, L. and L. Juhlin. 1971. Detection of penicillin allergy of the immediate type by radioimmunoassay of reagins (IgE) to penicilloyl conjugates. Clin. Allergy. 1:171-177.

21. Mamas, S., and F. Dray. 1979. Viroimmunoenzymoassay for detection of antipenicilloyl antibodies and penicilloyl residues: comparison of results obtained by radio, viro and enzymoimmunoassay. Ann. Inst. Pasteur Immunol. 130C:407-418.

22. de Haan, P., D. M. Boorsma, and G. L. Kalsbeek. 1979. Penicillin hypersensitivity. Determination and classification of anti-penicillin antibodies by the enzyme-linked immunosorbent assay. Allergy. 34:111-119.

23. Dixon, F. J., S. C. Bukantz, and G. J. Dammin. 1951. The effect of sensitization and X-radiation on the metabolism of $I^{131}$ labeled proteins. Science (Wash. DC). 113:274-276.

24. Edwards, R. G., D. A. Spackman, and J. M. Dewdney. 1982. Development and use of three new radioallergosorbent tests in the diagnosis of penicillin allergy. Int. Arch. Allergy Appl. Immunol. 68:352-357.

25. Adkinson, N. F. 1977. Quantitative studies of the IgE and IgG immune response to administration in man. Ann. Allergy. 39:73.

26. de Haan, P., and G. L. Kalsbeek. 1983. Induction of benzylpenicilloyl specific antibodies, including IgE, by long term administration of benzylpenicillin. Clin. Allergy. 13:563-569.

27. Swanson, M. C., E. Rosanoff, M. Gurwith, M. Deitch, P. Schnurrenberger, and C. E. Reed. 1987. IgE and IgG antibodies to $\beta$-propiolactone and human serum albumin associated with urticarial reactions to rabies vaccine. J. Infect. Dis. 155:909-913.

28. Day, J. F., R. W. Thornburg, S. R. Thorpe, and J. W. Baynes. 1979. Nonenzymatic glucosylation of rat albumin. Studies in vitro and in vivo. J. Biol. Chem. 254:9394-9400. 